\title{
EDITORIAL
}

\section{Fulfilling the promise of primary care spirometry}

\author{
P. Calverley
}

I $\mathrm{t}$ is a truth universally acknowledged that the simplest and most reliable way of assessing the function of the lungs is to make a spirometric measurement. Well, perhaps not universally acknowledged, but there is an increasing acceptance that the diagnosis of many lung diseases should involve a measurement of the functional capacity of the respiratory system and although this does not always tell us the whole truth [1, 2], it represents a substantial improvement on diagnostic criteria based solely on history examination and plain chest radiography. This is particularly true for diseases associated with airflow obstruction, such as chronic obstructive pulmonary disease (COPD), and those involving restriction of the lungs or chest wall, such as idiopathic pulmonary fibrosis or kyphoscoliosis. For doctors in primary care, the former is much more likely to be seen than the latter, and COPD along with bronchial asthma constitute the most frequent chronic respiratory diseases in this setting. While the importance of making an accurate diagnosis is not in doubt for patients with diabetes or chronic renal failure, we have been slow to adopt a similarly rigorous approach to respiratory conditions, especially COPD. Thanks to the efforts of many organisations, especially the European Respiratory Society (ERS) and the American Thoracic Society (ATS) [3], and also the Global Initiative for Chronic Obstructive Lung Disease (GOLD) programme [4], there is now a much wider appreciation of the need for objective diagnosis in common conditions such as COPD. As recent data from the Burden of Obstructive Lung Disease initiative has shown [5], this is a frequent and underappreciated problem, not only in developed European countries but particularly in many developing countries. One of our major tasks for the next decade will be to produce clear and consistent guidance as to how the relatively simple manoeuvres of spirometry can be applied as part of routine general care rather than just in specialist institutions with sophisticated pulmonary function laboratories.

There are several aspects to achieving this highly desirable goal. Some of these involve asking basic questions about how we should interpret spirometric results. The ERS and ATS have produced detailed recommendations in this respect [6], which are a terrific resource for the interested individual, especially when considering what normal values should be used to report the presence or absence of disease. This may appear to be a rather obscure issue but it has an enormous impact on the

\section{STATEMENT OF INTEREST: None declared}

CORRESPONDENCE: P. Calverley, Division of Infection and Immunity, Clinical Sciences Centre, University Hospital Aintree, Lower Lane, Liverpool, L9 7AL, UK. Fax: 44 1515295888. E-mail: pmacal@liverpool.ac.uk reported prevalence of a condition in a community. The problem is well illustrated by the age-related decline in lung function and, specifically, the ratio of forced expiratory volume in one second (FEV1) to forced vital capacity (FVC), which has been well documented [7]. As a result, individuals might be considered to have abnormal lung function and "early" COPD, when in fact this is a simple consequence of normal ageing. Even this has some problems as it is not clear whether the socalled "normal" processes are in themselves harmless and it is conceivable that the tendency to hyperinflation during exercise, which has even been observed in fit elderly subjects [8], might be worth treating if it contributes to symptoms. Some believe that we are in danger of "disease mongering" and that the early GOLD stage I patient who falls below the lower range of normal previously defined by the ERS but has an FEV1 $>80 \%$ predicted, is not, in fact, suffering from significant condition. This point has also been discussed recently [9] and it is clear that further work is needed to clarify the best way of expressing results. Reliance on a simple ratio of FEV1 to FVC may be misleading and there are attractions to looking instead at whether values for the definition of airflow obstruction fall below the lower limit of normal. Again, the definition of this variable is open to debate and large data sets will be needed that allow us to prospectively test proposals developed elsewhere before we can be confident that a change in the way we report data is legitimate and globally applicable. In the meantime, we need to be clear about what we are reporting and what the limitations might be. In this sense, the proposal of looking at patients of any age who fall into GOLD stage II and below (i.e. $\leqslant 80 \%$ pred) for COPD, is attractive as this seems to avoid most of the inherent "over-diagnosis" referred to above [10] and is in line with practice suggested by other national groups [11].

The debate concerning how airflow obstruction should be defined is important not only because of the strength with which different proponents hold their views but because it makes spirometry seem complicated and hard to interpret. In reality, for diagnostic purposes there is widespread agreement that if the structural impact of a disease is to be assessed, e.g. COPD or chronic asthma, it is preferable to consider spirometry performed after bronchodilator treatment; this was the approach used by the Burden Of Lung Disease (BOLD) group [5]. Others have commented on the need to make spirometry accessible to doctors working in primary care whose main interest is to use this as a tool rather than to become spirometry experts in their own right [12]. It is therefore particularly timely that this issue of the European Respiratory Journal (ERJ) features the summary of a meeting held in late 2005 in Belgium, which was devoted to addressing many of the practical issues relevant to spirometry in primary 
care [13]. A range of experts from the Netherlands and Belgium contributed to this meeting and the resulting summary contains a great deal of valuable information.

A number of questions were addressed as part of the meeting in Belgium, which initially considered why the primary care physician should perform spirometry in the first place. Data from several studies indicate that the average general practitioner (GP) will encounter eight new cases of asthma and seven new cases of COPD each year, with $\sim 50$ asthmatics and $\sim 60$ COPD patients remaining in their practice. If they focus on patients with prior respiratory symptoms, there is an increased chance of spirometry being positive, data that have been supported by large population surveys [14]. Certainly, there is a large body of undiagnosed disease, as general surveys in the UK have recently illustrated [15]. There is still an understandable reluctance to consider general spirometry screening as an aid to identifying COPD patients early in the disease, as the only intervention known to be beneficial in this setting is smoking cessation, which would be advocated anyway. However, at least for patients who are identified by selfpresentation or perhaps by case finding, there are data to suggest that knowledge of abnormal spirometric results will increase their rate of quitting [16]. These data do not suggest a disproportionately worse quit rate in individuals who were found to have normal lung function, which is the understandable concern that has been raised when considering wider smoking cessation campaigns. Moreover, the use of spirometry in general practice not only identifies and helps stage patients with obstructive lung disease, it also identifies others with mixed forms of lung function abnormality and, crucially, those who have been given a diagnosis of respiratory disease where there is no lung function abnormality at all [17]. Clearly, these data have to be interpreted in a clinical context as patients with mild asthma can have perfectly normal spirometry when tested, which emphasises the need to provide simple guidance and interpretation regarding what these tests mean, as well as focussing on the details of how they are performed.

The meeting in Belgium also considered how practical spirometry was in primary care, with results that were generally encouraging [13]. Previous suggestions that the identification of an FEV1 $<80 \%$ pred would be sufficient in its own right to diagnose lung disease have been challenged but there is increasing enthusiasm for the use of forced expiratory volume in six seconds, which, at least as a screening tool, offers both simplicity and reliability $[18,19]$. Primary care physicians are certainly capable of performing good-quality spirometry. The studies reviewed by DEROM et al. [13] show that, with appropriate training, office spirometry is both practical and gives good-quality data. What is less clear is the form that training should take; further studies, such as that described by EATON et al. [20], will be required in order to understand what components are most useful in the training regime, how often training should be repeated or reviewed, and whether prior familiarity with spirometric practice influences the success of the training programmes.

Undoubtedly, spirometry needs to be simple to use and there is a learning curve that favours frequent performance of this test rather than occasional measurement. One way of improving the interpretation of spirometric results is to use the internet to provide specific advice. This is attractive to earlier adopters of new technology and people who feel intuitively at home with computers, but it is reasonable to ask whether such a complicated process is really necessary. In a further paper in this issue of the ERJ, POELS et al. [21] have studied the impact of computerised spirometry expert interpretation on how well GPs diagnose disease. This is no easy task and PoELs et al. [21] adopted robust methodologies that should be studied by others who wish to gain a clear answer to these practical questions. The authors cluster randomised 78 family doctors and provided them with 10 standardised case descriptions, with half of the GPs receiving support from an expert computer system and the other half being provided with the spirometric data presented as a volume-time curve rather than a flow-volume presentation, which is the standard way in which data were presented in the Netherlands. The spirometric interpretation was made together with some clinical information and the physicians were asked to suggest what additional diagnostic tests they would like and how confident they were about the diagnosis made. A "GOLD standard" expert panel developed the "correct" answers against which the GPs performances were judged and the cases included covered a range of respiratory diagnosis, including asthma and COPD. The authors found, perhaps a little disappointingly, that use of the computerised expert support system did not affect the degree of agreement between the GPs and the expert panel for the diagnosis of COPD, asthma or the absence of respiratory disease. More diagnostic tests were suggested by those who received the expert support program but this may not translate into better clinical care.

This carefully conducted study acts as a model of the way in which behavioural interventions in respiratory disease can be tested scientifically. It also demonstrates that people promoting new interventions because they are "bound to help" may be quite mistaken. Perhaps the real lesson is that providing certain key data are available from spirometry, it is possible to integrate this with the clinical information and arrive at a generally satisfactory diagnostic formulation. Further work to identify which of these points is most important will help us educate the doctors of the future.

On a final note, the meeting held in Belgium [13] was dedicated to the memory of Prof. Romain Pauwels, a good friend and one of Europe's visionary respiratory physicians. One of Romain's greatest skills was his ability to see to the heart of a problem and propose simple solutions to complex issues. He had no doubt that lung function measurement could be performed to a good standard by many doctors and should be used much more now than was ever the case in the past. Doing so underlines the scientific basis of our discipline and emphasises the value of objective assessment, providing the tests we use are part of a holistic decision-making programme. We have made great strides in the area of primary care spirometry and as the papers published in the European Respiratory Journal this month illustrate, we are on track to achieve Romain's vision.

\section{REFERENCES}

1 O'Donnell DE, Lam M, Webb KA. Spirometric correlates of improvement in exercise performance after anticholinergic 
therapy in chronic obstructive pulmonary disease. Am J Respir Crit Care Med 1999; 160: 542-549.

2 Jones PW. Health status measurement in chronic obstructive pulmonary disease. Thorax 2001; 56: 880-887.

3 Celli BR, MacNee W, ATS/ERS Task Force. Standards for the diagnosis and treatment of patients with COPD: a summary of the ATS/ERS position paper. Eur Respir J 2004; 23: 932-946.

4 Rabe KF, Hurd S, Anzueto A, et al. Global strategy for the diagnosis, management, and prevention of chronic obstructive pulmonary disease: GOLD executive summary. Am J Respir Crit Care Med 2007; 176: 527-528.

5 Buist AS, McBurnie MA, Vollmer WM, et al. International variation in the prevalence of COPD (the BOLD Study): a population-based prevalence study. Lancet 2007; 370: 741-750.

6 Miller MR, Hankinson J, Brusasco V, et al. Standardisation of spirometry. Eur Respir J 2005; 26: 319-338.

7 Hardie JA, Buist AS, Vollmer WM, Ellingsen I, Bakke PS, Morkve O. Risk of over-diagnosis of COPD in asymptomatic elderly never-smokers. Eur Respir J 2002; 20: 1117-1122.

8 Johnson BD, Reddan WG, Pegelow DF, Seow KC, Dempsey JA. Flow limitation and regulation of functional residual capacity during exercise in a physically active aging population. Am Rev Respir Dis 1991; 143: 960-967.

9 Mannino DM, Buist AS. Global burden of COPD: risk factors, prevalence, and future trends. Lancet 2007; 370: 765-773.

10 Celli BR, Halbert RJ, Nordyke RJ, Schau B. Airway obstruction in never smokers: results from the Third National Health and Nutrition Examination Survey. Am J Med 2005; 118: 1364-1372.

11 National Collaborating Centre for Chronic Conditions. Chronic obstructive pulmonary disease. National clinical guideline on management of chronic obstructive pulmonary disease in adults in primary and secondary care. Thorax 2004; 59: Suppl. 1, 1-232.

12 Poels PJ, Schermer TR, Van Weel C, Calverley PM. Spirometry in chronic obstructive pulmonary disease. BMJ 2006; 333: 870-871.

13 Derom E, van Weel C, Liistro G, et al. Primary care spirometry. Eur Respir J 2008; 31: 197-203.

14 Calverley PM, Nordyke RJ, Halbert RJ, Isonaka S, Nonikov D. Development of a population-based screening questionnaire for COPD. COPD 2005; 2: 225-232.

15 Shahab L, Jarvis MJ, Britton J, West R. Prevalence, diagnosis and relation to tobacco dependence of chronic obstructive pulmonary disease in a nationally representative population sample. Thorax 2006; 61: 1043-1047.

16 Bednarek M, Gorecka D, Wielgomas J, et al. Smokers with airway obstruction are more likely to quit smoking. Thorax 2006; 61: 869-873.

17 Walker PP, Mitchell P, Diamantea F, Warburton CJ, Davies L. Effect of primary-care spirometry on the diagnosis and management of COPD. Eur Respir J 2006; 28: 945-952.

18 Jensen RL, Crapo RO, Enright P. A statistical rationale for the use of forced expired volume in 6 s. Chest 2006; 130: 1650-1656.

19 Lamprecht B, Schirnhofer L, Tiefenbacher F, et al. Sixsecond spirometry for detection of airway obstruction: a population-based study in Austria. Am J Respir Crit Care Med 2007; 176: 460-464.

20 Eaton T, Withy S, Garrett JE, Mercer J, Whitlock RM, Rea HH. Spirometry in primary care practice: the importance of quality assurance and the impact of spirometry workshops. Chest 1999; 116: 416-423.

21 Poels PJP, Schermer TRJ, Schellekens DPA, et al. Impact of a spirometry expert system on general practitioners' decision making. Eur Respir J 2008; 31: 84-92. 